\title{
CONTRASTIVE ANALYSIS OF PARTICLES IN CHINESE AND INDONESIAN LANGUAGE
}

\author{
Xiao Qin ${ }^{1,2)}$ dan Pratomo Widodo ${ }^{1)}$ \\ ${ }^{1)}$ Universitas Negeri Yogyakarta, Indonesia dan ${ }^{2)}$ Yunnan Minzu University, Tiongkok \\ email: xiaoqin190323@foxmail.com
}

\begin{abstract}
In Chinese and Indonesian, particles are often used and occupy an important place specifically in daily conversation. The study is aimed at distinguishing ways of using particles in order to propose suggestions that can be useful for Chinese learners in Indonesia. In this article, the authors describe the four pairs of particles to present similarities and differences in terms of syntax, semantics, and pragmatics and analyze the types and reasons in the errors of using particle's in Indonesian learners based on the HSK corpus. Where the data sources are examples of sentences containing particles, the technique of data collection is that of reading and note taking and the research instrument is a human instrument. Results show that the four pairs of particles have similarities and differences in syntax, semantics and pragmatics: all of them can be used at the end and middle of sentences, but not all can be used with other particles; all the pairs can translate between one another and can also be translated into other particles or adverbs. However, there are some particles that sometimes do not need to be translated; in different contexts, the four pairs of modal particles have different pragmatic functions.
\end{abstract}

Keywords: particle, Chinese, Indonesian, contrastive analysis

\section{ANALISIS KONTRASTIF PARTIKEL DALAM BAHASA TIONGHOA DAN BAHASA INDONESIA}

\begin{abstract}
Abstrak
Baik dalam bahasa Tionghoa maupun bahasa Indonesia, terdapat partikel yang kerap digunakan dan menduduki posisi penting dan khusus dalam percakapan sehari-hari. Penelitian ini bertujuan untuk memberikan pengetahuan dan saran kepada pelajar penutur bahasa Tionghoa yang ada di Indonesia agar dapat membedakan pemakaian partikel dalam kedua bahasa tersebut. Artikel ini mendeskripsikan empat pasang partikel dalam kedua bahasa dengan membandingkan persamaan dan perbedaannya. Perbedaan tersebut dari segi sintaksis, semantik, pragmatik. Selain itu, diuraikan pula jenis dan alasan kesalahan pemakaian partikel Tionghoa bagi pelajar Indonesia berdasarkan data korpus HSK. Sumber data adalah contoh kalimat yang mengandung partikel. Teknik pengumpulan data adalah teknik baca dan catat, serta instrumennya adalah human instrument. Hasil penelitian menunjukkan bahwa empat pasang partikel tersebut memunyai persamaan dan perbedaan baik dari segi sintaksis, semantik maupun
\end{abstract}


pragmatik. Persamaannya adalah semua partikel dapat digunakan baik di akhir maupun di tengah kalimat. Adapun semua pasangan partikel dapat diterjemahkan dalam bentuk partikel atau keterangan. Perbedaannya adalah tidak semua partikel dapat digunakan dengan partikel yang lain dan terdapat beberapa partikel yang kadang-kadang tidak perlu diterjemahkan. Empat pasang partikel memunyai fungsi pragmatik yang berbeda dalam konteks yang berbeda.

Kata Kunci: partikel, bahasa Tionghoa, bahasa Indonesia, analisis kontrastif

\section{PENDAHULUAN}

Seiring dengan eratnya kerjasama budaya dan pendidikan antara Tiongkok dan Indonesia, semakin banyak pula pelajar asal Tiongkok yang mempelajari bahasa Indonesia dan begitu pula sebaliknya. Namun, pengajaran bahasa Indonesia dan bahasa Tionghoa di kedua negara masih menemui beberapa kendala yang sulit ditemukan solusinya. Hal ini dikarenakan bahasa Tionghoa dan bahasa Indonesia termasuk dalam rumpun bahasa yang berbeda, yakni bahasa Tionghoa diklasifikasi sebagai rumpun bahasa Sino-Tibet (Sino-Tibetan languages), sedangkan bahasa Indonesia diklasifikasi sebagai rumpun bahasa Melayu-Polinesia (Malayo-polynesian language family). Oleh sebab itu, analisis kontrastif tata bahasa kedua bahasa tersebut memunyai peran yang signifikan dan dapat memberi kontribusi terhadap pengajaran dan pembelajaran kedua bahasa di masing-masing negara.

Permasalahan tata bahasa kerap ditemukan dalam pengajaran dan pembelajaran bahasa Indonesia dan bahasa Tionghoa. Misalnya, adanya kebingungan mengenai imbuhan, kata pinjaman, perbedaan urutan bahasa, cara pemakaian yang dan cara pemakaian kalimat aktif serta pasif. Yu (1993) mengungkapkan perihal tata bahasa Indonesia dalam bukunya yang berjudul Tata Bahasa Indonesia Modern yang ditulis berdasarkan praktek dan pengalaman dalam pengajaran bahasa Indonesia serta perkembangan bahasa Indonesia. $\mathrm{Yu}$ menyimpulkan bahwa fenomena tata bahasa Indonesia yang ada berkaitan dengan morfologi dan sintaksis. Liang (2017) membandingkan beberapa fenomena gramatikal dalam bahasa Indonesia dan bahasa Tionghoa dari tiga aspek, yaitu bentuk gramatikal, hubungan semantik dan fungsi pragmatik. Akan tetapi, masalah tata bahasa merupakan masalahyang masih dihadapi bagi pembelajar kedua bahasa.

Partikel adalah kata yang memiliki berbagai makna dan terdapat di bahasa Tionghoa dan bahasa Indonesia. Partikel dalam bahasa Tionghoa digunakan dalam bahasa baku dan lisan, meskipun pemakaiannya cenderung dalam bahasa lisan. Adapun dalam bahasa Indonesia sebagian besar partikel dipakai dalam bahasa lisan. Partikel kedua bahasa tersebut kerap dipakai dan menduduki tempat yang penting dalam proses komunikasi. Bahasa Tionghoa dan bahasa Indonesia termasuk dalam rumpun bahasa yang berbeda, namun dalam penggunaan partikel terdapat 
persamaan dan perbedaan. Peneliti mengenai partikel pada masing-masing bahasa telah dilakukan oleh para linguis, namun analisis kontrastif partikel bahasa Indonesia dan bahasa Tionghoa hanya sedikit dan hasilnya belum sangat berkaya. Oleh karena itu, analisis kontrastif perlu dilakukan guna mengetahui persamaan dan perbedaan yang terdapat dalam penggunaan partikel pada kedua tersebut.

Penelitian relevan mengenai partikel terdapat 4 jenis penelitian, yaitu sebagai berikut. Pertama, kajian penelitian partikel dalam bahasa Tionghoa yang berfokus pada penelitian fungsi pragmatik partikel, cara penerjemahan partikel, fungsi wacana partikel, makna intonasi partikel, studi sintaksis dan fungsi partikel dalam pengajaran bahasa Tionghoa di luar negeri beserta analisis kesalahan pemakaian partikel pada pembelajar bahasa Tionghoa sebagai bahasa kedua (Ping, S., 2007: 74-75; Jian, 2005:76-80; Feng, 2003; Juan, 2009: 5657; Liu, 2010; Ping, X., 2007; Andriani, 2017; Hua, 2002: 89-92; Jie, 2016: 82-86; Wei, 2015; d1l). Kedua, kajian penelitian partikel dalam bahasa Indonesia (Miyake, 2015: 103-114; Kulsum, 2012: 40-55). Ketiga, kajian penelitian kontrastif partikel antara bahasa Tionghoa atau bahasa Indonesia dengan bahasa yang lain (Lan, 2010; Zhi, 2013). Keempat, kajian penelitian kontrastif partikel antara bahasa Tionghoa dengan bahasa Indonesia. Dalam buku Tata Bahasa Indonesia Modern (Yu, 1993: 214-221), Yu membagi partikel menjadi dua kategori berdasarkan morfologi kata, yaitu partikel monolingual dan partikel sufiks yang ditambah di belakang kata. Liang juga mengungkapkan bahwa partikel sufiks yang ditambah di belakang kata termasuk -lah, -tah dan -kah, ketiganya harus ditulis dan diikuti dengan kata, sedangkan partikel monolingual termasuk deh, dong, kok, sih dan toh. Penjelasan tentang partikel ini memberi kontribusi yang signifikan bagi mahasiswa jurusan bahasa Indonesia di Tiongkok. Akan tetapi, ditemukan beberapa kekurangan dan penafsiran partikel yang belum lengkap. Misal pada partikel monolingual lain, yaitu nih, sih dan kan.

Dalam buku Tata Bahasa kontrastif dalam Bahasa Tionghoa dan Bahasa Indonesia, Liang (2017: 345) membandingkan berbagai pemakaian tata bahasa dalam bahasa Tionghoa dan bahasa Indonesia, misalnya perbandingan perbedaan urutan kalimat, kalimat pasif, dan lain-lain. Buku ini hanya membahas tata bahasa dalam bahasa baku tanpa memberikan perhatian pada bahasa lisan sehingga tidak melibatkan partikel. Liang juga berpendapat bahwa dalam pengajaran kedua bahasa diperlukan pembelajaran mengenai persamaan dan perbedaan partikel, misalnya partikel "啊 [a]”, “呀[ya]”, “吧[ba]”, “嘛[ma]”, “呢 [ne]" dalam bahasa Tionghoa dan "deh, dong, sih, toh" dalam bahasa Indonesia.

Berdasarkan pemaparan penelitian di atas, dapat diketahui bahwa hasil penelitian analisis kontrastif partikel antara bahasa Tionghoa dan bahasa Indonesia masih kurang dan penjelasannya belum cukup jelas. Misal pada penggunaan beberapa partikel bahasa Indonesia dan bahasa Tionghoa yang kerrap dipakai dalam komunikasi sehari-hari. Partikel tersebut memiliki kemirapan makna namun beda cara 
pemakaian. Oleh karena itu, rumasan masalah yang muncul adalah sebagai berikut: 1) Apa persamaan dan perbedaan partikel “吧[ba]”-"deh", “嘛[ma]”“dong”, “吗[ma]”-“kan/kah”, dan “呢 [ne]"-"sih" dalam bahasa Tionghoa dan bahasa Indonesia? 2) Bagaimana mengurangi kesalahan pemakaian partikel Tionghoa bagi pelajar Indonesia?

Adapun secara teoretis, hasil penelitian ini diharapkan dapat menambah khasanah ilmu bahasa khususnya terkait dengan analisis kontrastif partikel bahasa Tionghoa dan Indonesia. Secara praktis, hasil penelitian ini diharapkan dapat bermanfaat bagi pembelajar bahasa Indonesia dan bahasa Tiongkok khususna pengetahuan mengenai persamaan dan perbedaan pada cara pemakaian empat pasang partikel tersebut. Selain itu, hasil penelitian ini juga diharapkan dapat membantu peneliti lain dalam bidang linguistik dalam hal pengkajian bahasa Tionghoa dan bahasa Indonesia.

\section{METODE}

Jenis penelitian ini adalah penelitian kontrastif, satuan datanya adalah empat pasang partikel. Dalam penelitian ini, subjek penelitian merupakan kalimat dari buku tata bahasa, korpus HSK, kamus dan pengucapan sehari-hari. Objek penelitian adalah empat pasang partikel dalam subjek penelitian.

Penelitian ini merupakan hasil penelitian kontrastif antara kedua bahasa yang bertujuan untuk mengajukan beberapa saran untuk pelajar bahasa Tionghoa dan bahasa Indonesia di kedua negara. Artikel ini membandingkan partikel dalam bahasa Tionghoa dan bahasa Indonesia, lalu menguraikan persamaan dan perbedaan antara kedua bahasa. Sumber data dalam penelitian ini dikumpulkan dari buku Tata Bahasa Indonesia Modern (Yu, 1993), Kamus Lengkap Indonesia Tionghoa (Ji, 2000), percakapan sehari-hari dan korpus HSK (HSK dynamic Composition Corpus). Teknik yang digunakan dalam pengumpulan data adalah teknik baca dan teknik catat. Beberapa contoh kalimat yang mengandung partikel dalam kedua bahasa dibaca lalu dibandingkan dan dicatat persamaan dan perbedaannya. Instrumen yang dipakai adalah human instrument.

Prosedur pelaksanaan adalah sebagai berikut: 1) mengumpulkan data dari buku, kamus dan percakapan sehari-hari; 2) menganalisis data tersebut agar masing-masing dapat dibandingkan persaman dan perbedaan partikel dalam bahasa Tionghoa dan bahasa Indonesia dari segi sintaksis, semantik, dan pragmatik; 3) mengumpulkan data kesalahan pemakaian partikel Tionghoa dari pelajar Indonesia dengan data korpus HSK; dan (4) menganalisis data, yaitu menguraikan alasan dan jenis kesalahan serta mengajukan saran agar pelajar Indonesia dapat mengurangi kesalahan tersebut dalam pembelajaran bahasa Tionghoa mereka.

\section{HASIL DAN PEMBAHASAN Hasil}

Partikel “吧[ba]”-“deh”, “嘛[ma]”“dong”, “吗[ma]”-“-kah”, dan “呢[ne]”"sih" memunyai persamaan dan perbedaan dari segi sintaksis, semantik, dan pragmatik. Selain itu, pelajar bahasa 
Tionghoa di Indonesia juga sering pembelajarannya. Secara lengkap hasil melakukan beberapa kesalahan dalam penelitian ditunjukkan pada Tabel 1-4.

Tabel 1 Persamaan dan Perbedaan dari Segi Sintaksis

\begin{tabular}{lccc}
\hline & Akhir Kalimat & Tengah Kalimat & Dipakai dengan Partikel yang \\
& $\sqrt{ }$ & $\sqrt{ }$ & $\sqrt{ }$ \\
\hline 吧[ba] & $\sqrt{ }$ & $\sqrt{ }$ & $\times$ \\
deh & $\sqrt{ }$ & $\sqrt{ }$ & $\times$ \\
嘛[ma] & $\sqrt{ }$ & $\sqrt{ }$ & $\times$ \\
dong & $\sqrt{ }$ & $\sqrt{ }$ & $\times$ \\
吗[ma] & $\sqrt{ }$ & $\sqrt{ }$ & $\sqrt{ }$ \\
-kah & $\sqrt{ }$ & $\sqrt{ }$ & $\times$ \\
呢[ne] & $\sqrt{ }$ & $\sqrt{ }$ & $\times$ \\
sih & & & \\
\hline
\end{tabular}

Tabel 2 Persamaan dan Perbedaan dari Segi Semantik

\begin{tabular}{lccc}
\hline & $\begin{array}{c}\text { Saling } \\
\text { menerjemahkan }\end{array}$ & $\begin{array}{c}\text { Diterjemahkan ke } \\
\text { partikel yang lain atau } \\
\text { kata keterangan }\end{array}$ & $\begin{array}{c}\text { Partikel dalam bahasa Indonesia } \\
\text { tidak perlu di terjemahkan }\end{array}$ \\
\hline "吧[ba]"-"deh" & $\sqrt{ }$ & $\sqrt{ }$ & $\times$ \\
"嘛[ma]"-"dong" & $\sqrt{ }$ & $\sqrt{ }$ & $\sqrt{ }$ \\
"吗[ma]"-"-kah" & $\sqrt{ }$ & $\sqrt{ }$ & $\times$ \\
"呢[ne]"-"sih" & $\sqrt{ }$ & & \\
\hline
\end{tabular}

Tabel 3 Persamaan dan Perbedaan dari Segi Pragmatik

\begin{tabular}{|c|c|c|c|c|c|}
\hline \multicolumn{6}{|c|}{ Fungsi Pragmatik } \\
\hline $\begin{array}{l}\text { "吧[ba]"- } \\
\text { "deh" }\end{array}$ & $\begin{array}{l}\text { Menunjukkan } \\
\text { jawaban yang } \\
\text { jelas }\end{array}$ & $\begin{array}{l}\text { Menunjukkan } \\
\text { emosi } \\
\text { permintaan. }\end{array}$ & $\begin{array}{l}\text { Menunjukkan } \\
\text { emosi yang } \\
\text { belum tentu dan } \\
\text { berharap bahwa } \\
\text { pendengar dapat } \\
\text { memberikan } \\
\text { jawaban yang } \\
\text { akurat. }\end{array}$ & $\begin{array}{l}\text { Menunjukkan } \\
\text { emosi yang tidak } \\
\text { berdaya (helpless). }\end{array}$ & - \\
\hline $\begin{array}{l}\text { "嘛[ma]"- } \\
\text { "dong" }\end{array}$ & $\begin{array}{l}\text { Mengurangi } \\
\text { emosinya. }\end{array}$ & $\begin{array}{l}\text { Mengekspresikan } \\
\text { emosi } \\
\text { penyuruhan. }\end{array}$ & $\begin{array}{l}\text { Memberikan } \\
\text { suatu saran. }\end{array}$ & - & - \\
\hline $\begin{array}{l}\text { "吗 }[\mathrm{ma}] "- \\
\text { "-kah" }\end{array}$ & $\begin{array}{l}\text { Mengekspresikan } \\
\text { emosi tanya. }\end{array}$ & $\begin{array}{l}\text { Memberatkan } \\
\text { emosi dan } \\
\text { memperkuat } \\
\text { nada. }\end{array}$ & $\begin{array}{l}\text { Mengekspresikan } \\
\text { emosi yang tidak } \\
\text { sabar. }\end{array}$ & $\begin{array}{l}\text { "Sih" digunakan } \\
\text { untuk } \\
\text { menunjukkan } \\
\text { suatu hal sesuai } \\
\text { dengan logis. }\end{array}$ & $\begin{array}{l}\text { "Sih" digunakan } \\
\text { untuk } \\
\text { mengekspresikan } \\
\text { emosi terbalik. }\end{array}$ \\
\hline $\begin{array}{l}\text { "呢[ne ]"- } \\
\text { "sih" }\end{array}$ & $\begin{array}{l}\text { Mengajukan } \\
\text { pertanyaan biasa. }\end{array}$ & $\begin{array}{l}\text { Mengajukan } \\
\text { pertanyaan } \\
\text { tentang benar } \\
\text { atau salah. }\end{array}$ & $\begin{array}{l}\text { Mengajukan } \\
\text { pertanyaan } \\
\text { terbalik. }\end{array}$ & - & - \\
\hline
\end{tabular}


Tabel 4 Jenis Kesalahan Pemakaian Partikel pada Pelajar Indonesia

\begin{tabular}{cl}
\hline No. & \multicolumn{1}{c}{ Jenis } \\
\hline 1. & Kesalahan pemakaian partikel \\
2. & Kehilangan pemakaian partikel \\
3. & Kelebihan pemakaian partikel \\
\hline
\end{tabular}

\section{Pembahasan}

\section{Partikel dalam Bahasa Tionghoa dan Bahasa Indonesia}

Partikel "-kah" dalam bahasa Indonesia termasuk partikel sufiks ( $\mathrm{Yu}$, 1993:219) yang berarti bahwa partikel tersebut tidak dapat dipakai terpisah dengan kata lain, misalnya "apakah". Sebaliknya partikel "deh", "dong" dan "sih" termasuk partikel monolingual (Yu, 1993:219-220) yang berarti bahwa partikel tersebut dapat dipakai sendiri. Sedangkan “吧[ba]”, “嘛[ma]”, “吗 [ma]" dan “呢[ne]" dalam bahasa Tionghoa tidak dikategorikan sebagai partikel sufiks atau partikel monolingual, namun semuanya disebut sebagai partikel di akhir kalimat (modal particle at the end) yang berarti bahwa empat partikel tersebut hanya dipakai di dalam akhir kalimat atau frasa.

Untuk mengetahui persamaan dan perbedaan pemakaian keempat grup partikel, beberapa contoh kalimat diambil dari buku, kamus, dan percakapan sehari-hari. Akan tetapi, salah satu urutan kalimat baik di dalam bahasa Tionghoa maupun bahasa Indonesia belum selalu benar karena aturan urutan kalimat dalam kedua bahasa berbeda, maka dalam contoh berikutnya tidak semuanya sesuai dengan urutan sebenarnya.

\section{Persamaan dan Perbedaan dari Segi Sintaksis}

Ketika partikel mengekspresikan makna nada tertentu, kombinasi antara partikel dengan berbagai pola kalimat dibatasi oleh aturan struktur sintaksis (Juan, 2009:56). Bagian ini akan membandingkan lokasi sintaksis pada keempat grup partikel.

Partikel berbeda dengan interjection karena partikel bukan komponen independen sehingga tidak dapat digunakan sendirian tanpa ada partikel lain di dalam kalimat. Partikel di atas hanya dapat dilampirkan di belakang kalimat atau suatu komponen kalimat. Selain itu, partikel tidak mempunyai kemampuan devirasi apa pun dan tidak dapat ditambahkan di awal kata, di tengah kata atau di akhir kata sehingga tidak dapat membentuk kata yang baru. Dari bentuk kata-kata, partikel dapat dibagi menjadi dua kategori yaitu: (a) partikel tambahan akhiran yang meletakkan pada akhir kata, dan (b) partikel tambahan monolingual ( $\mathrm{Yu}$, 1993). Kategori tersebut dijelaskan dalam contoh-contoh kalimat adalah sebagai berikut.

Pertama, partikel “吧[ba]” dan "deh". Partikel “吧[ba]" dapat dipakai di akhir atau tengah kalimat, atau dipakai dengan partikel yang lain. Sementara itu, partikel "deh" dapat dipakai di akhir atau tengah kalimat, namun tidak dapat dipakai dengan partikel yang lain. Berikut ini contoh penggunaan partikel tersebut dipakai di akhir kalimat.

1. Ru guo ni zhen de xi huan, na $b a !$

2. Kalau kau benar-benar suka, Ambil deh! 
Dalam contoh kalimat tersebut dapat ditemukan bahwa partikel "ba" dan "deh" dipakai di akhir kalimat.

Contoh penggunaan partikel tersebut di tengah kalimat.

3. Baik apa guna banyak tawar-menawar.
deh,
4. Hao shen me tao jia huan jia.
ba, yong

Dalam contoh kalimat tersebut dapat ditemukan bahwa partikel "ba" dan "deh" dipakai di tengah kalimat, namun juga di akhir frasa dan dipakai sebelum tanda koma.

Contoh Partikel “吧[ba]" dipakai dengan partikel yang lain.

\section{Ni zao pan zhe gen wo li hun ne ba! \\ 6. Kamu sudah lama bercerai deh! berharap bahwa dengan aku}

Dalam contoh kalimat tersebut dapat ditemukan bahwa partikel "ba" dapat dipakai dengan partikel yang lain, misalnya "ne" dan menjadi "ne ba", namun partikel "deh" tidak dapat dipakai dengan cara begitu.

Kedua, petikel “嘛[ma]" dan "dong”. Lokasi sintaksis partikel “嘛[ma]” dan "dong" sama, yakni kedua partikel dapat dipakai di akhir atau tengah kalimat.

Contoh penggunaan partikel tersebut dipakai di akhir kalimat.

7. Bie zhe yang ma!
8. Jang begitu dong!

Dalam contoh kalimat tersebut dapat ditemukan bahwa partikel "ma" dan "dong" dipakai di akhir kalimat.
Contoh penggunaan partikel tersebut dipakai di tengah kalimat.
9. Bagi sedikit
dong
Kepada kami.
10. Fen yi dian dian
gei wo men.

Dalam contoh kalimat tersebut dapat ditemukan bahwa partikel "ma" dan "dong" dipakai di tengah kalimat, namun juga di akhir frasa dan dipakai sebelum tanda koma.

Ketiga, pertikel “呢[ne]" dan “sih". Partikel “呢[ne]” dapat dipakai di akhir atau tengah kalimat, atau dipakai dengan partikel yang lain. Dan "sih" dapat dipakai di akhir atau tengah kalimat, namun tidak dapat dipakai dengan partikel yang lain.

Contoh penggunaan partikel tersebut dipakai di akhir kalimat.
11. Di mana sih dia?
12. Zai na er ne ta?

Dalam contoh kalimat tersebut dapat ditemukan bahwa partikel "ba" dan "deh" dipakai di akhir kalimat.

Contoh penggunaan partikel tersebut dipakai di tengah kalimat.
13. Apa sih
yang bapak pikirkan
di larut malam begini?
14. Shen me ne Xian sheng zai zai zhe me wan xiang de shen ye

Dalam contoh kalimat tersebut dapat ditemukan bahwa partikel "ba" dan "deh" dipakai di tengah kalimat, namun juga di akhir frasa dan dipakai sebelum tanda koma.

Contoh penggunaan partikel “呢 
[ne]" dipakai dengan partikel yang lain.

15. Ni jiu deng zhe wo shuo zhe ju ne ba!

$$
\text { hua }
$$

16. Kamu sedang berbicara sih!

menunggu saya kalimat ini

Dalam contoh kalimat tersebut dapat ditemukan bahwa partikel "ba" dapat dipakai dengan partikel yang lain, misalnya "ne" menjadi "ne ba".

Keempat, partikel “吗[ma]" dan “-kah". Partikel “吗 [ma]” dan “-kah" memunyai arti yang sama, namun lokasi sintaksisnya jauh beda. Lokasi “吗[ma]" dapat dipakai di akhir atau tengah kalimat, sedangkan lokasi "-kah" hanya dapat dibelakang kata-kata.

Contoh penggunaan partikel tersebut dipakai di akhir kalimat.

17. Ni xiang xian zai qu chi fan ma?

18. Sekarang kamu pergi ke makan apakah? mau

Dalam contoh kalimat tersebut dapat ditemukan bahwa partikel "ma" dan "sih" dipakai di akhir kalimat. Yang berbeda adalah partikel "-kah" di belakang kata "apa".

Contoh penggunaan partikel tersebut dipakai di tengah kalimat.

19. Dia hendakkah belajar?

20. Ta xiang $m a \quad$ xue xi?

Dalam contoh kalimat tersebut dapat ditemukan partikel "ma" dan "-kah" dipakai di tengah kalimat, namun "-kah" tetap dipakai dengan kata yang lain.

\section{Persamaan dan Perbedaan dari Segi Semantik}

Fokus penelitian semantik merujuk pada sistem ekspresi makna bahasa yang tidak melibatkan penerapan yang spesifik. Semantik bertujuan untuk menjelaskan makna bahasa yang terpisah dari kalimat. Partikel adalah kata fungsi (syntactic expletive) yang digunakan untuk mengekspresikan berbagai nada dan emosi. Berbeda dengan partikel kata keterangan (modal adverb), partikel tidak memunyai arti apa pun dalam dirinya dan tidak memodifikasi komponen apa pun.

Meskipun partikel tidak memunyai arti dalam kedua bahasa, cara penerjemahan partikel dalam bahasa Tionghoa dan bahasa Indonesia memunyai arti yang signifikan karena penerjemah sering tidak tahu bagaimana menerjemahakan partikel. Dalam kebanyakan kasus, “吧[ba]” dan "deh", “ 嘛[ma]" dan “dong”, “呢[ne]" dan "sih", “吗[ma]" dan “-kah" dapat saling menerjemahkan. Artikel ini akan membahas partikel dari segi semantik agar membantu penerjemah pada kedua bahasa dapat lebih baik menerjemahkan partikel. Dengan demikian, beberapa kalimat dalam percakapan sehari-hari, buku, dan kamus diambil sebagai contoh untuk menjelaskan cara penerjemahan pada keempat partikel Indonesia dalam bahasa Tionghoa.

Pertama, partikel “吧[ba]” dan "deh". Penggunaan dan penerjemahan partikel “吧[ba]" dan "deh" dalam kalimat bahasa Indonesia dan China disajikan pada contoh-contoh kalimat berikut ini.

Contoh kalimat penggunaan partikel “deh" diterjemahkan ke “吧[ba]". 
21. Biar deh, jangan diladeni. "Deh" aja diterjemahkan Rang $b a$, bie lita. ke “吧[ba]". ta qu

22. Ayo deh, masuk! Lai $b a, \quad$ jin qu!

Contoh kalimat penggunaan partikel "deh" diterjemahkan ke partikel yang lain.

23. Deh, jangan banyak "Deh" omong. diterjemahkan ke Xing la, bie duo shuo le. partikel “啦[la]”. 24. Udah ini aja. "Deh" deh, diterjemahkan ke Hao le, jiu zhe yang ba. partikel "了 [1e]".

Kedua, partikel “嘛[ma]” dan "dong”. Penggunaan dan penerjemahan partikel “嘛[ma]” dan "dong” dalam kalimat bahasa Indonesia dan China disajikan pada contoh-contoh kalimat berikut ini.

Contoh kalimat penggunaan partikel “dong” diterjemahkan ke “嘛[ma]”.

25. Jangan Begitu dong! "Dong" Bie zhe yang $m a$ ! diterjemahkan

26. Tanya dulu dong! ke “嘛[ma]”. Wen wen xian ma!

Contoh kelimat penggunaan partikel "dong" diterjemahkan ke partikel yang lain atau tidak perlu diterjemahkan.

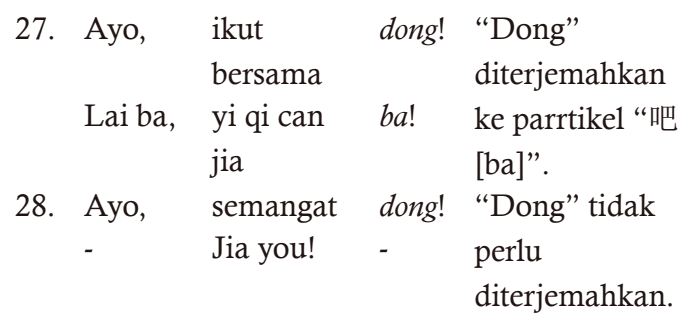

Ketiga, partikel “呢[ne]” dan “sih". Penggunaan dan penerjemahan partikel “呢[ne]" dan "sih" dalam kalimat bahasa
Indonesia dan China disajikan pada contoh-contoh kalimat berikut ini.

Contoh kalimat penggunaan partikel “sih" diterjemahkan ke “呢[ne]".

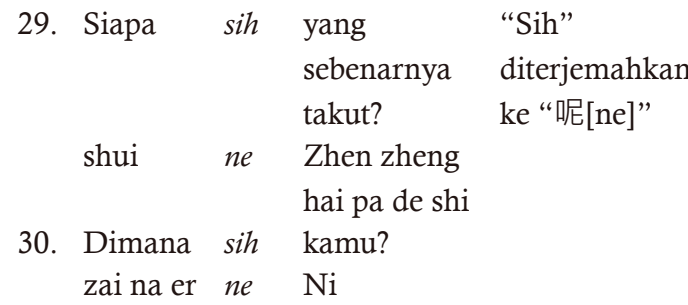

Contoh kalimat penggunaan partikel "sih" diterjemahkan ke partikel yang lain atau ke kata keterangan

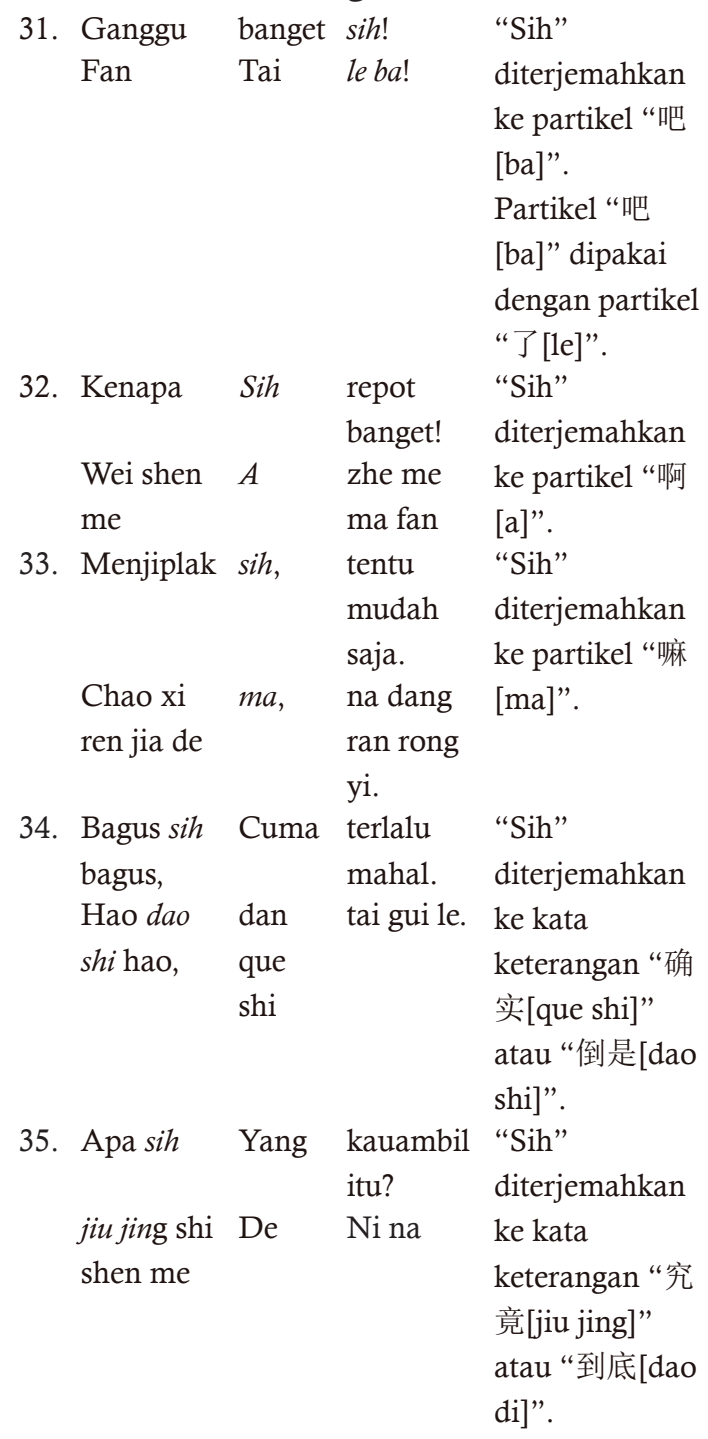


Keempat, “吗 [ma]” dan “-kah”. Penggunaan dan penerjemahan partikel “吗[ma]" dan "-kah" dalam kalimat bahasa Indonesia dan China disajikan pada contoh-contoh kalimat berikut ini.

Contoh kalimat penggunaan partikel "-kah" diterjemahkan ke “吗[ma]”.

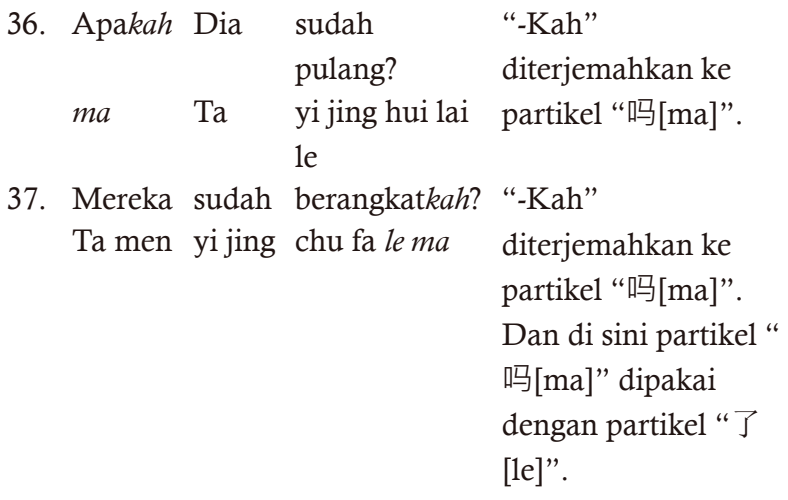

Contoh kalimat penggunaan partikel "-kah" diterjemahkan ke partikel yang lain atau tidak perlu diterjemahkan

\begin{tabular}{|c|c|c|c|c|}
\hline \multirow[t]{3}{*}{38.} & Di & manakah & mereka & "-Kah" \\
\hline & & & berdiri? & diterjemahkan \\
\hline & Zai & na er ne & $\begin{array}{l}\text { Ta men } \\
\text { zhan }\end{array}$ & $\begin{array}{l}\text { ke partikel “呢 } \\
\text { [ne]”. }\end{array}$ \\
\hline \multirow[t]{4}{*}{39.} & Apakah & itu? & & "-Kah" \\
\hline & she me $a$ & $\mathrm{Na}$ (shi) & & diterjemahkan \\
\hline & & & & ke partikel “啊 \\
\hline & & & & {$[\mathrm{a}] "$} \\
\hline \multirow[t]{6}{*}{40.} & Bagaimanakah & keadaan & sekarang? & "-Kah" \\
\hline & & ibumu & & diterjemahkan \\
\hline & zen me yang $l e$ & Ni mu & xian zai & ke partikel “了 \\
\hline & & qin de & & [le]". \\
\hline & & zhuang & & \\
\hline & & kuang & & \\
\hline \multirow[t]{3}{*}{41.} & Anda suka & Kopikah & atau & "-Kah" tidak \\
\hline & minum apa, & & tehkah? & perlu \\
\hline & $\begin{array}{l}\text { Nin xi huan he } \\
\text { shen me, }\end{array}$ & ka fei & $\begin{array}{l}\text { hai shi } \\
\text { cha? }\end{array}$ & diterjemahkan. \\
\hline
\end{tabular}

\section{Persamaan dan Perbedaan dari Segi Pragmatik}

Seperti disebutkan di atas, partikel digunakan untuk mengekspresikan berbagai nada dan emosi, misalnya keraguan, kecurigaan, kesungguhan, penekanan dan sebagainya. Partikel digunakan dalam tengah kalimat untuk menunjukkan jeda dan digunakan dalam akhir kalimat untuk menegaskan emosi.

Pragmatik mempelajari makna bahasa dalam penggunaan dan salah satu tugasnya yaitu bagaimana peserta dalam percakapan memahami makna bahasa dalam konteks dari arti kata dan frasa di luar konteks (yaitu, linguistic meaning) (Schmitt, diterjemahkan oleh Ning, 2016: 86). Sama halnya dengan semantik, pragmatik juga meneliti makna bahasa, namun lebih cenderung pada makna bahasa dalam konteks tertentu, tindakan bicara, prasangka, makna percakapan dan sebagainya. Misalnya prakmatik mempelajari bagaimana memrediksi makna yang tersembunyi, dan bagaimana perbedaan makna bahasa dalam kalimat yang berbeda.

Berdasarkan analisis di atas dapat diketahui berbagai cara penerjemahan partikel "deh", "dong", "sih" dan "-kah". Dan dalam kebanyak kasus, keempat partikel dapat diterjemahkan ke “吧 [ba]”, “嘛[ma]”, “呢[ne]” dan “吗[ma]”. Padahal dalam kedua bahasa, delapan partikel memunyai makna yang berbeda dalam keadaan yang berbeda sesuai dengan konteks, namun dalam keadaan yang keempat kelompok partikel dapat saling menerjemah, maknanya contoh terbatas. Bagian ini akan membahas bermacam makna keempat kelompok partikel dalam konteks situasional 
(situational context) yang berbeda.

Pertama, fungsi pragmatik pada partikel “吧[ba]" dan "deh". Fungsi pragmatik partikel “吧[ba]" dan “deh" dalam kalimat bahasa Indonesia dan China disajikan pada contoh-contoh kalimat berikut ini.

Contoh kalimat penggunaan partikel “吧[ba]" dan "deh" menunjukkan jawaban yang jelas.

\begin{tabular}{llll}
\hline 42. & Ni zao pan zhe & gen wo li hun & ne $b a !$ \\
43. & $\begin{array}{l}\text { Kamu sudah lama } \\
\text { berharap bahwa }\end{array}$ & $\begin{array}{l}\text { bercerai dengan } \\
\text { aku }\end{array}$ & deh! \\
\hline
\end{tabular}

Misalnya contoh kalimat 42 dan 43, dalam kalimat pembicara telah tahu kenyataan itu, yaitu pendengarnya telah lama mau bercerai dengan dia.

Contoh kalimat penggunaan partikel “吧[ba]" dan "deh" menunjukkan emosi permintaan.

$\begin{array}{lll}\text { 44. Beli } & \text { baju ini } & \text { aja deh! } \\ \text { 45. Mai } & \text { zhe jian yi fu } & b a !\end{array}$

Misalnya dalam contoh kalimat. 44 dan 45 , pembicara memakai partikel “吧 [ba]" dan "deh" dalam kedua bahasa karena dia ingin meminta pendengarnya membeli baju yang dia tunjukkan, namun bukan baju yang lain.

Contoh kalimat penggunaan partikel “吧[ba]" dan "deh" menunjukkan emosi yang belum tentu dan berharap bahwa pendengar dapat memberikan jawaban yang akurat.

46. Ani tidak mungkin jatuh sakit deh!

47. Ani bu ke neng sheng bing le $b a$ !

Misalnya dalam contoh kalimat 46 dan 47 , pembicara tidak percaya bahwa
Ani tidak mungkin akan jatuh sakit, alasannya mungkin Ani sangat sehat, jadi dia memakai partikel untuk mengekspresikan emosinya yang belum tentu dan ingin mengetahui apa yang terjadi pada pendengarnya..

Contoh kalimat penggunaan partikel “吧[ba]" dan "deh" menunjukkan emosi yang tidak berdaya (helpless).

\begin{tabular}{ll}
\hline 46. Baik deh, & ini aja. \\
47. Hao $b a$, & jiu zhe yang. \\
\hline
\end{tabular}

Misalnya dalam contoh kalimat No. 46 dan 47, pembicara memakai partikel karena dia telah tiada cara yang lain dapat mengubah kenyataan sekarang.

Kedua, fungsi pragmatik pada partikel “嘛[ma]" dan "dong”. Fungsi pragmatik partikel “嘛[ma]” dan "dong” dalam kalimat bahasa Indonesia dan China disajikan pada contoh-contoh kalimat berikut ini.

Contoh kalimat penggunaan partikel “嘛[ma]" dan "dong” digunakan untuk mengurangi emosinya.

\begin{tabular}{llll}
\hline No. & \multicolumn{3}{l}{ Contoh kalimat dalam kedua bahasa } \\
\hline \multirow{2}{*}{ 48. } & Jangan & Begitu & dong! \\
& Bie & Zhng & ma! \\
\hline
\end{tabular}

Dalam contoh kalimat 48, jika pembicara mengucapkan kalimat ini dengan nada naik, fungsi pragmatik partikel "ma" dan "dong" merupakan mengurangi emosinya, misalnya kedua orang berpacaran dan pacar perempuan marah, lalu pacar lelaki mengucapkan kalimat tersebut dengan nada naik untuk meminta maaf dari pacar perempuannya.

Contoh kalimat penggunaan partikel “嘛[ma]" dan "dong” digunakan untuk 
mengekspresikan emosi penyuruhan.

49. Jangan begitu dong!

Dalam contoh kalimat yang sama, jika pembicara mengucapkan kalimat ini dengan nada turun, fungsi pragmatiknya "dong" merupakan .emosi penegasan yang mengekspresikan emosi penyuruhan. Namun dalam bahasa Tionghoa, biasanya nada "ma" adalah nada naik, makanya tiada kasus seperti itu.

Contoh kalimat penggunaan partikel “嘛[ma]" dan "dong” digunakan untuk memberikan suatu saran.

\section{Tanya Dulu dong! \\ Wen wen Xian ma!}

Misalnya dalam contoh kalimat 50, pembicara memakai "dong" dan "ma" untuk menyaran pendengarnya bertanya dulu, namun bukan langsung melakukan sesuatu. Sebaliknya, kalau pembicara tidak memakai partikel, yakni pembicara mengucapkan bahwa "Tanya dulu" atau "Wen wen xian", emosinya jauh berbeda karena itu berarti bahwa pembicara menyusuh pendengar melakukan tindakan bertanya dulu.

Ketiga, fungsi pragmatik pada partikel “呢[ne]" dan "sih". Fungsi pragmatik partikel “呢[ne]" dan "sih" dalam kalimat bahasa Indonesia dan China disajikan pada contoh-contoh kalimat berikut ini.

Contoh kalimat penggunaan partikel “呢[ne]" dan “sih" digunakan untuk mengekspresikan emosi tanya. $\begin{array}{lll}\text { 51. Apakah } & \text { Dia } & \text { sudah pulang? } \\ \text { 52. } m a & \text { Ta } & \text { yi jing hui lai le }\end{array}$

Misalnya dalam contoh kalimat 51 dan 52, partikel digunakan untuk bertanya sesuatu.

Contoh kalimat penggunaan partikel “呢[ne]" dan “sih" digunakan untuk memberatkan emosi dan memperkuat nada.

53. Kenapa sih repot banget!
Zen me ne na me ma fan

Misalnya dalam contoh kalimat 53, partikel digunakan untuk menegaskan bahwa hal itu sangat repot.

Contoh kalimat penggunaan partikel “呢[ne]" dan “sih" digunakan untuk mengekspresikan emosi yang tidak sabar.

$\begin{array}{lll}\text { 54. Dimana } & \text { sih } \\ \text { zai na er } & \text { ne } & \mathrm{Ni}\end{array}$

Dalam contoh kalimat 54, partikel digunakan untuk bertanya lokasi pendengar dengan emosi dan nada naik yang tidak sabar karena mungkin pembicara telah menunggu pendengar cukup lama.

Contoh kalimat penggunaan partikel "sih" digunakan untuk menunjukkan suatu hal sesuai dengan logis (Yu, 1993: 220).

$\begin{array}{ll}\text { 55. Engkau jatuh? } & \text { Tidak hati- sih! } \\ \text { hati }\end{array}$

Misalnya contoh kalimat 55, "sih" digunakan untuk menunjukkan kenyataan bahwa "Engkau jatuh" sesuai logis karena "Engkau" tidak hati-hati. 
Tetapi kalau dalam keadaan ini, "sih" diterjemahkan ke “嘛[ma]" melainkan bukan “呢[ne]”.

Contoh kalimat penggunaan partikel "sih" digunakan untuk mengekspresikan emosi terbalik (Yu, 1993:220).

56. Bagus sih bagus, cuma terlalu mahal.

Misalnya contoh kalimat 56, "sih" digunakan untuk mengekspresikan emosi terbalik. Itu berarti bahwa meskipun (kualitas sesuatu) bagus, namun mahal, jadi pembicara tidak akan membelinya. Tetapi kalau dalam keadaan ini, "sih" diterjemahkan ke “确实[que shi]” atau “ 倒是 [dao shi]” melainkan bukan “呢 [ne]".

Keempat, fungsi pragmatik pada partikel “吗[ma]" dan “-kah". Fungsi pragmatik partikel “吗[ma]” dan “-kah" dalam kalimat bahasa Indonesia dan China disajikan pada contoh-contoh kalimat berikut ini.

Contoh kalimat penggunaan partikel “吗 [ma]” dan “-kah" digunakan untuk mengajukan pertanyaan biasa.

57. Apakah dia sudah pulang? Ma Ta yi jing huilaile

Dalam contoh kalimat 57, kedua partikel digunakan untuk mengajukan pertanyaan yang bertujuan untuk mengetahui informasi.

Selain itu, lokasi "-kah" menentukan fokus pertanyaan. Sedangkan dalam contoh kalimat yang sama, lokasi "ma" sama, namun fungsi pragmatiknya sama dengan "-kah". Contoh kalimat sebagai berikut.
58. Diakah yang hendak belajar? Subjek: dia

59. Dia hendakkah belajar? Predikat: hendak

60. Dia hendak belajarkah? Objek: belajar

Dalam contoh kalimat 58, "-kah" di belakang subjek (dia), itu berarti bahwa pembicara ingin mengetahui bahwa siapa yang hendak belajar, yaitu "dia" atau oran yang lain.

Dalam contoh kalimat 59, "-kah" di belakang predikat (hendak), itu berarti bahwa pembicara ingin mengetahui keinginan subjek (dia), yaitu apakah subjek (dia) masih ingin belajar tidak.

Dalam contoh kalimat 59, "-kah" di belakang objek (belajar), itu berarti bahwa pembicara ingin mengetahui apa yang subjek (dia) ingin lakukan, yaitu subjek (dia) ingin belajar atau bermain atau bernyanyi atau bagaimana.

Partikel “吗 [ma]” dan “-kah" digunakan untuk mengajukan pertanyaan tentang benar atau salah.

\begin{tabular}{llll}
\hline 61. Dia & Tidak suka durian & iyakah? \\
Ta & bu xi huan liu lian & shi ma? \\
\hline
\end{tabular}

Dalam contoh kalimat 61, kedua partikel digunakan untuk mengajukan pertanyaan petunjuk tentang benar atau salah, dan jawabannya dalam contoh sejenisnya hanya "Iya" atau "Bukan/ Tidak".

Partikel “吗 [ma]” dan “-kah" digunakan untuk mengajukan pertanyaan terbalik.

$\begin{array}{lll}\text { 62. Bukankah itu } & \text { dia? } \\ \text { bu shi ma Na ge ren } & \text { ta }\end{array}$

Dalam contoh kalimat 62, kedua partikel digunakan untuk mengajukan pertanyaan terbalik. Itu berarti bahwa 
pembicara telah memunyai jawaban, yaitu "Itu dia".

\section{Jenis dan Alasan Kesalahan Pemakaian \\ Partikel dalam Bahasa Tionghoa bagi Pelajar Indonesia Berdasarkan Data Korpus HSK}

Uraian pada bagian sebelumnya telah membandingkan persamaan dan perbedaan partikel “吧[ba]”-"deh”, “嘛 [ma]"-“dong”, “吗 [ma]"-“kan/kah", dan “呢[ne]”-“sih". Padalah partikel dalam kedua bahasa masih ada banyak, namun kedelapan partikel sering digunakan dalam percakapan seharihari. Namun karena perbedaan tata bahasa antara kedua bahasanya, pelajar bahasa Tionghoa di Indonesia sering salah memakai partikel “吧[ba]”, “嘛 [ma]", “吗[ma]” dan “呢[ne]”.

Jenis kesalahan yang utama dibagi menjadi tiga jenis, yakni (a) kesalahan pemakaian beberapa partikel, (b) kehilangan pemakaian partikel yang harus dipakai, dan (c) keleibihan pemakaian partikel (Andriani, 2017:2326). Dengan demikian, berdasarkan data korpus HSK dapat mengetahui jenis kesalahan pemakaian partikel dalam bahasa Tionghoa bagi pelajar Indonesia.

Pertama, jenis kesalahan pemakaian partikel dalam bahasa Tionghoa bagi pelajar Indonesia berdasarkan data korpus HSK

Kesalahan pemakaian partikel “吧 [ba]"

Sesuai dengan data korpus HSK, kalimat yang mengisi partikel “吧[ba]" yang dibuat oleh pelajar Indonesia sejumlah 122, antara lain kalimat yang salah memakai “吧[ba]” sejumlah 8, yakni 1 kalimat salah memakai partikel,
1 kalimat dihilangkan pemakaian partikel dan 6 kalimat menambah partikel pada keadaan yang seharusnya tidak memerlukan pemakaian partikel. Contoh kalimat dengan jenis kesalahan yang berbeda adalah sebagai berikut.

(1) Kesalahan pemakaian partikel

Contoh kalimat bahasa Tionghoa:

Wo ren wei ge xing ye shi yi ge ren $b a$.

Terjemahannya:

Saya pikir bahwa bintang penyanyi juga adalah orang deh.

Dalam kalimat tersebut, yang perlu digunakan bukan “吧[ba]” melainkan “ 啊[a]" karena "penyanyi adalah orang" itu kenyataan, namun fungsi pragmatik " 吧[ba]" membuat kenyataan itu menjadi hal yang belum tentu.

(2) Kehilangan pemakaian partikel

Contoh kalimat bahasa Tionghoa:

Tai mei yi si $b a$ !

Terjemahannya:

Terlalu tidak menarik deh!

Dalam contoh kalimat tersebut, terjemahannya benar, namun dalam bahasa Tionghoa, dalam kalimat sejenisnya harus dipakai tua partikel, yaitu “了吧[le ba]”.

(3) Kelebihan pemakaian partikel

Contoh kalimat bahasa Tionghoa:

Qian wan bie ba zi nü yong yuan dang zuo xiao hai zi, yao xiang xin ta men $b a$.

Terjemahannya:

Jangan selalu pikir bahwa anak-anak sebagai anak kecil, harus percaya mereka deh!

Kalimat tersebut tidak perlu memakai partikel dalam bahasa Tionghoa. 
Kesalahan pemakaian partikel “吧[ba]"

Dalam data korpus HSK, kalimat yang mengisi partikel “吧[ba]" yang dibuat oleh pelajar Indonesia sejumlah 14, dan semuanya benar.

Kesalahan pemakaian partikel "吗 [ma]"

Dalam data korpus HSK, kalimat yang mengisi partikel “吧[ba]" yang dibuat oleh pelajar Indonesia sejumlah 101, antara lain kalimat yang salah memakai “吗[ma]” sejumlah 7, yakni 7 kalimat salah memakai partikel, “吗 [ma]" salah dipakai dengan (1)-“呢[ne]”, (2)-“嘛[ma]” dan (3)-“吧[ba]”. Contoh kalimat sebagai berikut.

(1) Contoh kalimat bahasa Tionghoa:

Er fu mu ma?

Terjemahannya:

Bagaimanakah orang dua?

Dalam kalimat tersebut, yang perlu digunakan bukan “吗[ma]” dan “-kah" melainkan “呢[ne]" dan "sih" baik dalam bahasa Tionghoa maupun dalam bahasa Indonesia.

(2) Contoh kalimat dalam bahasa Tionghoa:

Liu xing ge qu ye shi yi ge wen hua de jiao liu ma.

Terjemahannya:

Lagu popular juga merupakan salah satu pertukaran budayakah.

Jika dalam bahasa Indonesia, kalimat terjemahannya benar dan akan menjadi kalimat tanya, namun dalam kalimat aslinya adalah kalimat deklaratif. Oleh karena itu, yang perlu digunakan bukan " 吗 [ma]" dan “-kah" melainkan “嘛[ma]” dan "dong".
(3) Contoh kalimat dalam bahasa Tionghoa:

$\mathrm{Ru}$ guo ni de cheng ji bu shi hao de, na ni ye hui gan dao yi zhong ya li ma?

Terjemahannya:

Jika nilai kamu tidak bagus, jadi kamu juga akan merasa tekanankah?

Dalam kalimat tersebut, yang perlu digunakan bukan “吗[ma]" dan “-kah" melainkan “吧[ba]" dan "deh" karena pembicara sudah memunyai jawaban, yaitu "jika nilai tidak bagus akan merasa tekanan", namun bukan ingin bertanya.

Kesalahan pemakaian partikel "呢[ne]"

Dalam data korpus HSK, kalimat yang mengisi partikel “吧[ba]" yang dibuat oleh pelajar Indonesia sejumlah 272, antara lain kalimat yang salah memakai “呢[ne]” sejumlah 2, yakni 1 kalimat salah memakai partikel dan 1 kalimat menambah partikel pada keadaan yang tidak perlu memakainya. Contoh kalimat dengan jenis kesalahan yang berbeda sebagai berikut.

(1) Kesalahan pemakaian partikel: contoh itu silakan melihat contoh (1) tentang Kesalahan pemakaian partikel “吗 [ma]”.

(2) Kelebihan pemakaian partikel

Contoh kalimat dalam bahasa Tionghoa:

Suo yi ne, wo ren wei dai gou de jie jue $n e, \ldots . .$. .

Terjemahannya:

Maka sih, saya pikir bahwa penyelesaian "kesenjangan generasi" sih ....... .

Dalam contoh di atas dipakai dua kali “呢[ne]", namun kalau dipakai di 
depan/belakang, makanya tidak perlu dipakai di belakang/depan lagi.

\section{Alasan Kesalahan Pemakaian Partikel dalam Bahasa Tionghoa bagi Pelajar Indonesia Berdasarkan Data Korpus HSK}

Pertama, baik di Tiongkok maupun Indonesia belum ada buku tentang perbandingan partikel dalam kedua bahasa. Pengajaran di sekolah biasanya menekankan bahasa baku, namun jarang ditemukan penjelasan tentang aturanaturan bahasa lisan.

Kedua, pengaruh migrasi negatif bahasa ibu mengakibatkan bahwa pelajar Indonesia berpikir secara metode tata bahasa Indonesia. Misalnya contoh di atas dalam data korpus HSK:

Contoh kalimat dalam bahasa Tionghoa:

Liu xing ge qu ye shi yi ge wen hua de jiao liu ma.

Terjemahannya:

Lagu popular juga merupakan salah satu pertukaran budayakah.

Padahal kalimat terjemahannya benar dan akan menjadi kalimat tanya, namun dalam konteks bahasa Tionghoa di dalam korpus HSK, itu salah.

Ketiga, guru di Indonesia yang mengajari bahasa Tionghoa kebanyakan keturunan Tionghoa, meskipun mereka dapat bahasa Tionghoa, namun itu juga berbeda dengan keadaan di Tiongkok. Selain itu, pengajaran partikel memang merupakan kesulitan yang besar dalam pengajarannya karena aturannya terlalu luas sesuai dengan konteks yang berbeda.

Keempat, banyak siswa di Indonesia belum memunyai kesempatan untuk belajar di Tiongkok, makanya tiada lingkungan yang lebih bagus sehingga penerapan bahasa lisannya hanya terbatas dari dalam buku saja. berhenti di dalam buku.

\section{Saran untuk Mengurangi Kesalahan}

Baik dalam pengajaran guru atau pembelajaran siswa akan menemui kesalahan pemakaian partikel seperti contoh tersebut. Jika cukup jelas tentang cara pemakaian akan mengurangi kemungkinan kesalahan sebesar mungkin, oleh karena itu, penulis mengajukan beberapa saran untuk guru dan siswa.

Pertama, saran untuk mengurangi kesalahan penggunaan partikel pada guru. Para guru sendiri harus mempelajari cara pemakaian partikel secara jelas karena bahasa lisan jauh berbeda dengan bahasa tulis? Dengan demikian, dalam pengajaran guru dapat membandingkan persamaan dan perbedaan partikel dalam kedua bahasa agar siswa lebih mengetahui perbedaannya.

Meskipun susah memberi lingkungan bahasa kepada siswa, guru seharusnya menerapkan latihan ke dalam kehidupan sehari-hari agar siswa dapat merasa fungsi pragmatik yang berbeda pada partikel yang sama dalam konteks yang berbeda sehingga para siswa dapat belajar secara langsung. Jika ada waktu dan uang yang cukup, lebih baik guru menulis buku pembelajaran tentang partikel agar menyediakan bahan referensi bagi guru dan siswa.

Kedua, saran untuk mengurangi kesalahan penggunaan partikel pada siswa. Untuk mengurangi pengaruh migrasi negatif bahasa ibu, siswa sebaiknya belajar bahasa ibunya dengan baik, 
lalu belajar bahasa Tionghoa agar dapat mengetahui perbedaannya dengan jelas dan tidak akan memcampur kedua bahasa. Jika ada kesempatan lebih baik siswa dapat memunyai kesempatan untuk belajar di Tiongkok karena itu akan memberikan lingkungan bahasa yang lebih bagus.

\section{SIMPULAN}

Baik dalam bahasa Tionghoa maupun bahasa Indonesia terdapat banyak partikel. Artikel ini mengambil keempat pasang partikel yang kerap dipakai dalam kedua bahasa sebagai contoh untuk membandingkan persamaan dan perbedaannya dari segi sintaksis, semantik dan pragmatik. Pelajar bahasa Tionghoa di Indonesia juga sering salah memakai partikel tersebut. Dengan demikian, jenis dan alasan kesalahan pemakaian partikel bagi pelajar Indonesia berdasarkan korpus HSK diuraikan dan diberikan saran kepada guru dan siswa untuk mengurangi kemungkinan kesalahannya. Diharapkan hasil penelitian ini dapat bermanfaat untuk pelajar bahasa Tionghoa di Indonesia dan pelajar bahasa Indonesia di Tiongkok beserta peneliti lain yang terkait.

Artikel ini belum melibatkan semua partikel dan hanya mengambil beberapa sebagai contoh karena keterbatasan tulisan, waktu, dan energi. Oleh karena itu, jika peneliti selanjutnya dapat meneliti semua partikel dalam kedua bahasa akan sangat bermanfaat bagi pengajaran dan pembelajaran bahasa Tionghoa dan Bahasa Indonesia. Selain itu, bagi pelajar antara siswa di kedua negara, masih terdapat banyak masalah tata bahasa yang perlu diperhatikan dan diteliti agar pembelajarannya dapat lebih maju.

\section{UCAPAN TERIMA KASIH}

Dalam penulisan artikel ini, bagian tersulit adalah proses pengumpulan data. Hal ini dikarenakan banyak waktu yang diperlukan guna mengetahui cara pemakaian partikel dalam kedua bahasa. Oleh karena itu, ucapan terima kasih diberikan kepada beberapa orang Indonesia dan orang Tiongkok yang membantu membuat percakapan, yaitu dosen, teman sejawat, narasumber yang terlibat dalam penelitian ini. Di sini susah menyebutkan semua nama mereka, tetapi secara tulus diucapkan terima kasih atas bantuan, kesabaran dan perhatian kepada mereka. Selain itu, peneliti juga ingin secara tulus berterima kasih kepada penulis buku dan kamus yang sebagai referensi dan sumber data dalam hasil penelitian ini.

\section{DAFTAR PUSTAKA}

Andriani, F. (2017). Research on mistakes the use of the modal particles "Ba", "Ma", "Ne" and Teaching Design for Indonesian Students. Master's thesis. Faculty of Arts: Jilin University.

Feng, Z. X. (2003). A discourse analysis of mood particle $\mathrm{Ba} \mathrm{Ne}$ and $\mathrm{A}$ in Tionghoa Chinese. Doctoral's dissertation. Shanghai Normal University.

Hua, X. L. (2002). An analysis of foreign students' errors of Chinese modal particles. Journal of Zhejiang Normal University (Social Sciences). 27 (5), 8992.doi:10.3969/j.issn. 1001 5035.2002.05.020.

Ji, L. L. (2000). Kamus Lengkap Indonesia Tionghoa. Jakarta: PT Elex Media Komputindo Kelompok Gramedia. 
Jian, S. R. (2005). Four Functions of the Toned Words at the End of Sentences. Journal of Nantong University (Social Sciences Edition). 21 (2), 76-80. doi:10.3969/j.issn.16732359.2005.02.015.

Jie, S. (2016). On the translation of Chinese ending modal particle "Ne" in Thunderstorm. Journal of Nanjing University of Science and Technology (Social Science Edition). 29 (3), 82-86.

Juan, X. H. (2009). Penelitian syntax dan fungsi pada partikel "Ba" dalam pengajaran bahasa Tionghoa sebagai bahasa asing. Journal of Changchun University of Science and Technology (Higher Education Edition). 4 (5), 56-57.

Kulsum, U. (2012). Membandingkan partikel fatis deh dan dong dalam bahasa Indonesia. Ranah. 1 (1), 4055. https://doi.org/10.26499/rnh. v1i1.15.

Lan, H. D. (2010). Penelitian kontrastif pada partikel dalam bahasa Tionghoa dan bahasa Thailand. Master's thesis. Faculty of Arts: Guangxi University of Nationalities.

Liang, H. M. (2017). Tata Bahasa kontrastif dalam Bahasa Tionghoa dan bahasa Indonesia. Guangzhou: Jinan University Press.

Liu, Y. (2010). The primary research of the mood particle in Chinese Courses for Foreigners. Master's thesis. Hunan University.

Miyake, Y. (2015). Makalah disajikan pada the Second International workshop on Information Structure of Austronesian Languages.

Pragmatic particles and information structure in colloquial Indonesian dialogue. Tokyo University of Foreign Studies, Tokyo, Jepang. Hal 102114. https://core.ac.uk/download/ pdf/41886357.pdf.

Ping, S. (2007). Study on the expression word in modern Chinese. Journal of Hetan Teachers College. 27 (5), 74-75. $\mathrm{d}$ o $\mathrm{i}: 10.3969 / \mathrm{j}$. issn.1671-0908.2007.05.049.

Ping, X. (2007). An error analysis on Chinese modal particles of Englishspeaking Chinese learners. Master's thesis. East China Normal University. Schmitt, N. (2016). An Introduction to Applied Linguistics. ( $\mathrm{Xu}$ Jingning, transl.). Beijing: Beijing World Publishing Corporation (Original book, 2002).

Wei, W. X. (2015). On the English translation of modal particles "Ma", "Ne" and "Ba" in modern ChineseTaking Teahouse as an example. Master's thesis. Huaibei Normal University.

Yu, Z. Q. (1993). Tata Bahasa Indonesia Modern. Beijing: FLTRP (Foreign Language Teaching and Research Press).

Zhi, W. (2013). Penelitian kontrastif pada partikel dalam bahasa Tionghoa dan bahasa Laos. Master's thesis. Faculty of Arts: Guangxi University of Nationalities. 